\title{
Resiquimod Gel CD11301
}

National Cancer Institute

\section{Source}

National Cancer Institute. Resiquimod Gel CD11301. NCI Thesaurus. Code C148143.

A topical gel containing the Toll-like receptor (TLR) agonist resiquimod, an imidazoquinolinamine, with potential immunomodulating activity. Upon topical application, the resiquimod gel CD11301 binds to TLR7 and 8, which are found mainly on dendritic cells (DCs), macrophages, and B-lymphocytes, and activates the TLR signaling pathway, which results in the induction of the nuclear translocation of transcription activator nuclear factor kappa-B (NF-kB) and activation of other transcription factors. Subsequently, NF-kB-dependent gene expression is induced and cytokine production increases, especially interferon-alpha (INF-a), which results in the enhancement of Thelper 1 (Th1) immune responses. In addition, topical application of resiquimod appears to activate epidermal Lang erhans cells, leading to enhanced activation of T-lymphocytes. 